\title{
Students tidy online presence before applying to medical school and residency
}

\author{
n Cite as: CMAJ 2018 September 24;190:E1146-7. doi: 10.1503/cmaj.109-5629
}

Posted on cmajnews.com on Sept. 4, 2018.

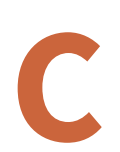
ould a drunken photo or poorly worded joke stand in the way of admission to medical school or a residency program? It's a possibility that physician hopefuls have to think about.

"I'm pretty sure I culled through all my photos to make sure that, for example, if there was a photo of me at a party, there wasn't any obvious drinking going on in the background," said Dr. Britt Harrison, a family medicine resident at McMaster University who wrote an article on social media etiquette for the International Journal of Medical Students. "I changed my Facebook name to be a nickname, and that's something most of my peers did."
A 2013 study of 600 medical school admissions officers in the United States found that $9 \%$ routinely looked at applicants' social media presence, and half said unprofessional social media content could negatively affect a student's chance of acceptance. With the growth of social media platforms, it's likely this practice has only increased.

Dr. Geneviève Moineau, president and CEO of the Association of Faculties of Medicine of Canada (AFMC), said her association does not have a policy regarding the use of social media in the medical school application process. As far as she is aware, "there is no school that is systematically looking at applicant's social

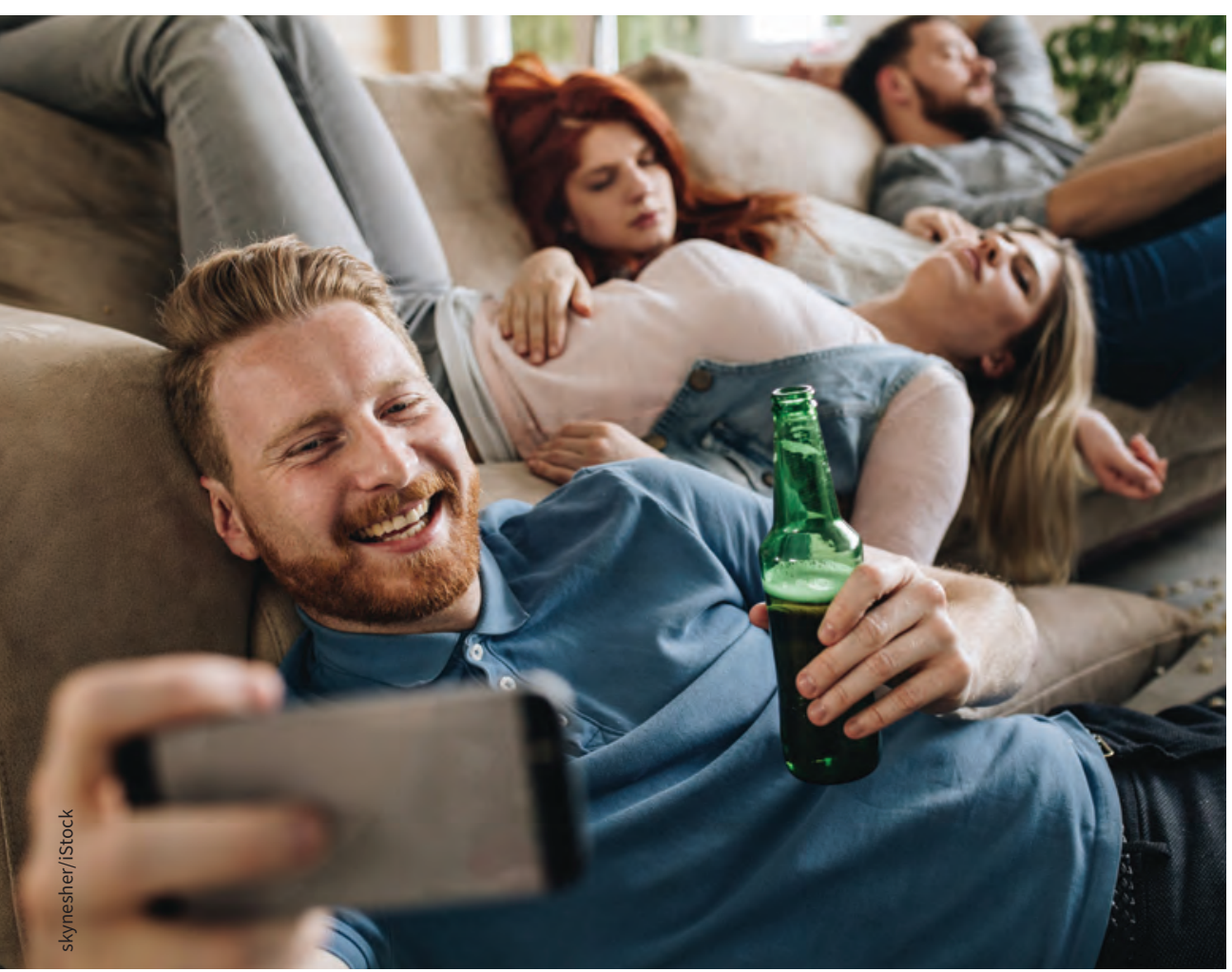

Applying to medical school? Might be time to cull your online photos.

media profiles." But it's possible those sitting on undergraduate or graduate committees are looking up some candidates, Moineau said. "What's public is public ... You can expect that your online profile could be looked at for any application."

Recognizing the importance of social media, medical schools have created codes of conduct for social media and the Internet in recent years. "Students will be reprimanded, as appropriate, if they do post anything or put anything on social media that is inappropriate or that is against privacy policies," explains Moineau.

In 2010, the Canadian Federation of Medical Students (CFMS) released a digital professionalism policy that all medical students are expected to follow. According to Dr. Kaylynn Purdy, outgoing vicepresident of education for the federation, social media screening hasn't been raised as a concern to the CFMS, so it's not a topic the organization has addressed. But her class was told to Google themselves ahead of the residency matching process "to see if there are things we might want to try and have removed," said Purdy, a graduate of the Northern Ontario School of Medicine and incoming resident in neurology at the University of Alberta.

The CFMS's social media guide advises medical students that "there is no such thing as a private social media network" and that students are responsible for anything they write on social media, whether under their own names or pseudonyms. "Social media should be treated as a public forum akin to an op-ed in a newspaper," the guideline states.

Dr. Michael Arget, president of Resident Doctors of Canada, said he was told by someone on a selection committee for a family medicine residency program that 
"we don't have time" to look at candidates' social media profiles. Still, he suspects the practice could happen in smaller residency programs.

According to Arget, medical students should be used to being careful about their social media presence. "As part of this profession, we are held to a higher standard," he said. In his first year of medical school, the associate dean told a lecture hall of students, "Anything you wouldn't want to be posted on the front page of the Sunday newspaper for your grandmother to see, you don't want to post on social media," recalls Arget.

Social media can, however, be a useful tool for medical students and residents. Networks like Twitter can be used to show they're engaged in leadership and thinking about new ideas for health systems. "Many of our peers use Twitter to network, and people get to know you," said Purdy. There is a fine line, though, between sharing ideas and revealing opinions that could be misunderstood. Social media should reflect who you are, she says, "but there's been times I've tweeted things that I've deleted afterward."

Social media use may lead to missteps that become barriers to certain opportunities, but it could also open doors to other opportunities, said Harrison. "Even in med school, they're starting to talk about branding yourself on social media."

Wendy Glauser, Toronto, Ont. 